\title{
Effects of on-pump versus off-pump coronary artery bypass graft surgery on right ventricular function
}

Isabelle Michaux, MD, a,d Miodrag Filipovic, MD, ${ }^{a}$ Karl Skarvan, MD, ${ }^{a}$ Stephan Schneiter, MD, ${ }^{\mathrm{b}}$ Regina Schumann, MD, ${ }^{\text {a }}$ Hans-Reinhard Zerkowski, MD, ${ }^{\mathrm{c}}$ Franziska Bernet, MD, ${ }^{\mathrm{c}}$ and Manfred D. Seeberger, MD ${ }^{\mathrm{a}}$

Objectives: Right ventricular dysfunction is a possible cause of cardiac failure after coronary surgery. The use of cardiopulmonary bypass is regarded as a major cause for its occurrence, and it has been postulated that performing coronary surgery without cardiopulmonary bypass might reduce ventricular dysfunction. Therefore, this prospective, randomized, controlled study tested the hypothesis that off-pump coronary surgery would better preserve right ventricular systolic and diastolic function than conventional bypass surgery.

Methods: Fifty patients scheduled for elective coronary artery bypass surgery were randomly assigned to conventional or off-pump surgery. Right ventricular function was assessed by intraoperative transesophageal echocardiography immediately before and after coronary surgery. Right ventricular ejection fraction was used as a marker of global systolic function and tricuspid early/late (atrial) ratio as a marker of the global diastolic function. Peak systolic and early diastolic velocities of the lateral tricuspid annulus were studied to assess systolic and diastolic function in the area of the right ventricular free wall.

Results: Surgery was completed according to randomization in 48 of 50 patients. Preoperative characteristics were similar in both groups. Intraoperative differences between the two groups included a higher volume of allogeneic blood transfusion in the conventional surgery group. At the end of surgery, global systolic right ventricular function was similarly maintained and diastolic function similarly impaired in both groups. There were no significant intergroup differences in any of the echocardiographic markers of right ventricular function.

From the Department of Anesthesia, ${ }^{\text {a }}$ Department of Internal Medicine, Division of Cardiology, ${ }^{\mathrm{b}}$ and Department of Surgery, Division of Cardiothoracic Surgery, ${ }^{\mathrm{c}}$ University Hospital Basel, Basel, Switzerland; Department of Intensive Care Medicine, ${ }^{d}$ Mont-Godinne University Hospital, Université Catholique de Louvain, Louvain, Belgium.

The study was supported in part by the Swiss Society of Anesthesiology and Resuscitation.

Received for publication Sept 13, 2005; revisions received Dec 22, 2005; accepted for publication Jan 13, 2006.

Address for reprints: Isabelle Michaux, MD, Department of Intensive Care Medicine, Mont-Godinne University Hospital, Université Catholique de Louvain, B-5530 Yvoir, Belgium (E-mail: isabelle. Michaux@rean.ucl.ac.be).

J Thorac Cardiovasc Surg 2006;131:1281-8

$0022-5223 / \$ 32.00$

Copyright (C) 2006 by The American Association for Thoracic Surgery

doi:10.1016/j.jtcvs.2006.01.035

Conclusions: Off-pump surgery did not better preserve right ventricular systolic and diastolic function than did conventional coronary surgery.

$\mathrm{R}$ ight ventricular (RV) dysfunction is a possible cause of cardiac failure after cardiac surgery and has a high mortality rate. ${ }^{1,2}$ Major reasons for complications of cardiac surgery are the need for hypothermic cardiac arrest, aortic crossclamping, and exposure to a cardiopulmonary bypass circuit. ${ }^{3,4}$ It has been postulated that avoidance of these factors by performing off-pump coronary artery bypass (OPCAB) surgery might reduce perioperative morbidity and improve outcome. ${ }^{3}$ Whether OPCAB surgery can fulfill these expectations, or to which degree, is yet unclear. ${ }^{5}$ Nevertheless, prospective studies have consistently found a smaller myocardial enzyme release up to 24 hours after surgery in the OPCAB groups, ${ }^{6-8}$ suggesting a smaller degree of intraoperative myocardial damage. One might speculate that reduced myocardial damage will result in a smaller incidence of postoperative heart failure, especially in patients with preexisting RV or left ventricular (LV) dysfunction. However, it is unclear whether smaller myocardial enzyme release correlates with better ventricular function in OPCAB patients. One study reported that LV function is preserved after multivessel $\mathrm{OPCAB}$ surgery but did not include a comparison with 


\author{
Abbreviations and Acronyms \\ $\mathrm{CCABG}=$ conventional coronary artery bypass \\ grafting \\ $\mathrm{E} / \mathrm{A}$ ratio $=$ early/atrial ratio \\ $\mathrm{E}_{\mathrm{a}} \quad=$ early peak diastolic velocity \\ $\mathrm{LV}=$ left ventricular \\ $\mathrm{OPCAB}=$ off-pump coronary artery bypass surgery \\ $\mathrm{RV} \quad=$ right ventricular \\ $\mathrm{S}_{\mathrm{a}} \quad=$ peak systolic velocity \\ TDI = tissue Doppler imaging
}

patients undergoing conventional coronary artery bypass grafting $(\mathrm{CCABG}),{ }^{9}$ and there are no studies comparing the short-term effect of OPCAB versus CCABG surgery on RV function. Therefore, we performed this prospective, randomized, controlled study to assess and compare the effects of CCABG and OPCAB surgery on RV function. Given the smaller myocardial enzyme release, we hypothesized that OPCAB surgery would better preserve RV systolic and diastolic function than CCABG.

\section{Patients and Methods}

The prospective, randomized, controlled study was performed with approval from the Basel Committee on Human Research, and every patient provided written informed consent. Fifty consecutive patients scheduled for elective CABG surgery and for whom the surgeon regarded off-pump and on-pump techniques as equally suitable were included. Exclusion criteria were as follows: redo or emergency surgery; preoperative hemodynamic instability requiring continuous inotropic medication; lack of sinus rhythm or complete bundle branch block or atrioventricular delay greater than 240 milliseconds on the preoperative electrocardiogram; intermittent or permanent ventricular pacing before surgery; and moderate or severe mitral or tricuspid valvular disease or atrial septal defect on the preoperative transthoracic echocardiogram. A sample size of 25 patients per group was calculated on the basis of a pilot study to allow for detection of a $20 \%$ intergroup difference in RV ejection fraction and RV-E/A at the end of surgery ( $\alpha=.05$, $\beta=.20 ; 2$-tailed unpaired $t$ test). A computer-generated random list was used to assign patients to the CCABG or the OPCAB group.

\section{Patient Monitoring and Anesthetic Management}

Anesthetic management was performed in a standardized way according to the routine procedure for patients undergoing cardiac surgery at our institution, as previously described. ${ }^{10,11}$ In brief, anesthesia was induced with thiopentone or etomidate and maintained with midazolam, fentanyl, and isoflurane. Muscle relaxation was achieved by repeated boluses of pancuronium, and controlled mechanical ventilation with $50 \%$ oxygen in air was provided to achieve normocapnia. All patients were continuously monitored by 2-lead electrocardiography (II, $\mathrm{V}_{5}$ ), pulse oximetry, and invasive measurement of arterial blood pressure and central venous pressure. A pulmonary artery catheter was inserted in all OPCAB patients and in 4 of $25 \mathrm{CCABG}$ patients. To prevent hypotension during surgery, each OPCAB patient received $500 \mathrm{~mL}$ of hydroxyethyl starch $6 \%$ in $0.9 \%$ sodium chloride injection (B. Braun, Melsungen, Germany) after induction of anesthesia. Each CCABG patient received 500 to $1000 \mathrm{~mL}$ hydroxyethyl starch $6 \%$ as priming solution for cardiopulmonary bypass. Additional hydroxyethyl starch $6 \%$ was administered during the operation as clinically indicated.

If pharmacologic support was required during weaning from cardiopulmonary bypass or at any time during OPCAB surgery, low-dose epinephrine or norepinephrine $\left(0.03\right.$ to $0.07 \mu \mathrm{g} \cdot \mathrm{kg}^{-1}$. $\min ^{-1}$ each) was given and the dose adjusted according to the hemodynamic response. Single or repeated intravenous boluses of esmolol $\left(0.25-0.5 \mathrm{mg} \cdot \mathrm{kg}^{-1}\right)$ or propranolol $\left(2-3 \mu \mathrm{g} \cdot \mathrm{kg}^{-1}\right)$ were used to reduce the heart rate, if needed.

\section{Surgical Procedure}

The surgical techniques were standardized and all operations were performed by one surgeon. A midline sternotomy was performed in all patients. The left internal thoracic artery was always prepared as the only arterial graft for subsequent anastomosis to the left anterior descending coronary artery or a diagonal branch. Venous grafts were always attached to the aorta. Heparin was administered intravenously to achieve an activated clotting time greater than 480 seconds in CCABG patients and greater than 400 seconds in OPCAB patients. In $\mathrm{CCABG}$ patients, an arterial cannula was placed in the ascending aorta (Jostra, BIOMEDICA Medizinprodukte $\mathrm{GmbH}$, Wien, Austria) and a 2-stage venous cannula in the right atrium (Stöckert, Sorin Group Deutschland GmbH, München, Germany). Two membrane oxygenators (Affinity, Medtronic, Cardiovascular Systems, Minneapolis, Minn, and QuadroxJostra Inc, Austin, Tex) with a tubing system that included an arterial line filter were used. Surgery was performed with normothermic cardiopulmonary bypass, and antegrade cold blood cardioplegia was used for myocardial protection. Blood aspirated from the surgical field was subsequently reinfused into the patient. Distal vein grafts to coronary anastomoses were completed first and then the left internal thoracic artery was anastomosed. During reperfusion, the bypass grafting was completed with proximal anastomoses to the ascending aorta. Atrial or sequential pacing, as needed, was used to wean the patient from cardiopulmonary bypass if the spontaneous sinus rhythm was below 80 beats/min. After separation from cardiopulmonary bypass, protamine was given to reverse the effects of heparin.

OPCAB surgery was performed as described by Sergeant and associates. ${ }^{12}$ The pericardium was suspended to the left side. In contrast, the right-sided pericardium was never suspended to achieve mobility of the heart while distal anastomoses were performed. Inspiratory oxygen fraction was increased to $80 \%$ throughout the grafting period and reduced to $50 \%$ again after completion of the last graft. A V-shaped sponge was fixed down on the right posterior mediastinum halfway on the line joining the inferior vena cava to the left inferior pulmonary vein. Closing and extracting the $\mathrm{V}$-shaped sponge retracted the left atrium and the left ventricle. The epicardium in the area of the distal anastomosis was immobilized by an Octopus III epicardial stabilizer (Medtronic, Minneapolis, Minn). To decrease the duration of ischemia and to achieve a bloodless surgical field, we used intracoro- 
nary perfusion catheters in coronary vessels with a diameter greater than $1.5 \mathrm{~mm}$. The left internal thoracic artery was routinely the first graft performed. Shed blood was collected from the operating field and retransfused (COBE BRAT 2, COBE Cardiovascular, Inc, Arvada, Colo). Atrial pacing was used if the spontaneous sinus rhythm was less than 65 beats/min. The decision to switch to cardiopulmonary bypass during the procedure was based on significant hemodynamic instability and/or ventricular arrhythmia.

\section{Echocardiographic Recordings, Measurements, and Calculations}

Transesophageal echocardiographic studies were performed by one investigator using a Sonos 5500 ultrasound system and a multiplane 4-7 MHz transesophageal echocardiography probe (Philips, Best, The Netherlands). Baseline study data were acquired before opening of the sternum and data at the end of the operation after closure of the sternum. With the use of the respiratory signal on the screen of the imaging system, study recordings were always performed at end-expiration, that is, on the last cardiac cycle before mechanical lung inflation. Three recordings of each view were digitally acquired per study period and stored for subsequent off-line analysis. The mean values of three measurements by a reader who was blinded to all other study data, including surgical technique, were used for analysis. So that intrareader and interreader variability could be determined, a random sample of $25 \%$ of the data was submitted twice to the first investigator and once to a second investigator. The variabilities were calculated as the mean absolute difference between two readings divided by their mean and expressed as percentage.

Two-dimensional recordings of the 4-chamber view were used for measurements of the RV end-diastolic area and end-systolic area. The midesophageal RV inflow-outflow view was recorded for measuring the end-diastolic and end-systolic lengths of the right ventricle, which were defined as the distance between the lateral annulus of the tricuspid valve and the lateral annulus of the pulmonary valve. The RV end-diastolic and end-systolic volumes were calculated on the basis of these measurements according to the formula: $\mathrm{RV}$ volume $=2 / 3 \cdot$ area $\cdot$ length. ${ }^{13}$ Cardiac output was then calculated according to the formula: cardiac output $=$ (end-diastolic volume - end-systolic volume) · heart rate. Midesophageal 4-chamber, 2-chamber, and long-axis views were used for segmental wall motion analysis of the left ventricle using the 16-segment model and the 5-grade scale of wall motion according to current guidelines. ${ }^{14}$ Two experienced readers independently performed wall motion analyses, and consensus readings were performed when initial scores of the two readers were not in agreement. Presence of new segmental wall motion abnormality at the end of surgery was diagnosed if wall motion in a segment deteriorated by two or more grades. ${ }^{10}$ The wall motion score index was calculated by dividing the sum of the scores of all readable segments by the number of readable segments at baseline and after surgery. We also calculated a score for the segments depending on the right coronary artery, that is, the 3 inferior segments. Pulsed-wave Doppler echocardiography was performed in the midesophageal 4-chamber view to study tricuspid inflow velocities. The sample volume was placed between the tips of the open tricuspid leaflets; peak early (E) and late (A [atrial]) velocities were subsequently measured and the E/A ratio calculated. Pulsed-wave tissue Doppler imaging (TDI) was performed in the transgastric RV inflow view to study motion of the posterolateral annulus of the tricuspid valve. Measured tissue Doppler imaging parameters included early peak diastolic velocity $\left(\mathrm{E}_{\mathrm{a}}\right)$ of the lateral annulus and peak systolic velocity $\left(\mathrm{S}_{\mathrm{a}}\right)$.

Echocardiographic outcome parameters included cardiac output that was used to study global RV function, ejection fraction to study systolic RV function, and tricuspid E/A ratio to study diastolic RV function. Peak systolic and diastolic velocities of the tricuspid annulus, $S_{a}$ and $E_{a}$, were used to study systolic and diastolic function of the posterolateral RV free wall.

Echocardiographic assessment of the left ventricle included 2-dimensional recordings of the transgastric short-axis view. These recordings were used for measuring LV end-diastolic area and end-systolic area and for calculation of LV fractional area change. Pulsed-wave Doppler echocardiography was used to study mitral inflow velocities in the midesophageal 4-chamber view. The sample volume was placed between the tips of the open mitral leaflets, peak early (E) and late (A) velocities subsequently measured, and the E/A ratio calculated.

\section{Statistical Analysis}

Continuous variables are presented as mean $\pm \mathrm{SD}$ and [median]. All analyses of continuous variables were performed by nonparametric tests, that is, by a Mann-Whitney $U$ test for unpaired variables or Wilcoxon signed-rank test for paired variables. Dichotomous variables are presented as numbers and percentages; the Fisher exact test was used for their analysis. Analyses were performed on an "intention to treat" basis. All tests were 2-tailed. All statistical analyses were performed using an SPSS for Windows 12.0 computer package (SPSS Inc, Chicago, Ill).

\section{Results}

Surgery was completed according to randomization and standardized surgical plan in 48 of the 50 patients. Conversion to cardiopulmonary bypass was performed in 2 of the 25 patients randomized to the OPCAB group because of marked hemodynamic instability during retraction of the heart. All patients with a significant stenosis of the right coronary artery received a venous graft to this artery, except in 6 patients whose right coronary artery was completely occluded ( 2 in the CCABG group and 4 in the OPCAB group). A significant stenosis of the RV branch was observed in 4 patients ( 2 in the CCABG group and 2 in the $\mathrm{OPCAB}$ group). These RV branches were not revascularized because they were regarded as too small $(<1.5 \mathrm{~mm})$ for receiving a bypass graft. Seven patients had a slow initial recovery and stayed in the intensive care unit more than 48 hours (4 in the CCABG group and 3 in the OPCAB group). However, there were no major complications and 30-day mortality was null in both groups.

\section{General Perioperative Characteristics}

The two groups had similar preoperative characteristics (Table 1). No patient had documented previous RV infarction or pulmonary hypertension. Intraoperative differences 
TABLE 1. Preoperative characteristics of 50 patients undergoing on-pump versus off-pump coronary artery bypass surgery

\begin{tabular}{lcc}
\hline & On-pump & Off-pump \\
\hline No. of patients & 25 & 25 \\
Age (y) & $65 \pm 8[66]$ & $61 \pm 9[60]$ \\
Female gender & $4(16)$ & $4(16)$ \\
Weight (kg) & $78 \pm 14[76]$ & $75 \pm 10[74]$ \\
Height (cm) & $171 \pm 8[174]$ & $170 \pm 7[172]$ \\
EuroScore & $3.0 \pm 2.6[3.0]$ & $2.4 \pm 2.5[2.0]$ \\
Three-vessel coronary artery & $20(80)$ & $19(76)$ \\
$\quad$ disease & $10(40)$ & $11(44)$ \\
95\% stenosis of right & & \\
$\quad$ coronary artery & $58 \pm 16[62]$ & $57 \pm 16[60]$ \\
Ejection fraction (\%) & $9(36)$ & $10(40)$ \\
Angina pectoris CCS III-IV & $10(40)$ & $13(52)$ \\
Previous myocardial infarction & $8(32)$ & $8(32)$ \\
Diabetes mellitus & $18(72)$ & $13(52)$ \\
Hypertension & & \\
Long-term medication & $23(92)$ & $23(92)$ \\
$\quad$ Beta-receptor blockers & $10(40)$ & $6(24)$ \\
$\quad$ ACE inhibitors & $3(12)$ & $2(8)$ \\
$\quad$ Insulin &
\end{tabular}

Values are mean \pm SD [median] or number (\%). Preoperative characteristics are similar in both groups. CCS, Canadian Cardiovascular Society; $A C E$, angiotensin-converting enzyme.

between the two groups included a higher incidence and volume of allogeneic blood transfusion and a lower hemoglobin level at the end of surgery in the CCABG group (Table 2). The volume of Ringer's lactate administered was also higher in $\mathrm{CCABG}$ than in OPCAB patients. At the end of surgery, the average heart rate was significantly higher than at baseline in both groups, and it was significantly higher in the CCABG than in the OPCAB group. The use of atrial pacing at the end of surgery was significantly more frequent in the CCABG group. Peak troponin I levels in the first 24 hours after surgery were markedly elevated in both groups, but significantly higher in the CCABG group than in the OPCAB group.

Echocardiographic findings. Two-dimensional images and tricuspid flow velocity recordings of good quality could be obtained in all study patients at both study periods (Table 3 and Figure 1). RV TDI signals of sufficient quality could be obtained in 44 patients at baseline, that is, in 22 patients in the CCABG and 22 patients in the OPCAB group, and in 40 patients at the end of surgery, that is, in 20 patients in each group. Reproducibility of all echocardiographic measurements was high. Intrareader variability ranged from $2 \%$ $\left(\mathrm{S}_{\mathrm{a}}, \mathrm{E}_{\mathrm{a}}\right)$ to $7 \%$ (RV ejection fraction), interreader variability from 5 to $14 \%$.

Cardiac output did not significantly change after surgery and systolic ejection fraction remained stable in both groups. There were decreases in RV end-systolic and end-diastolic volumes after revascularization in both groups, but these were more pronounced in the CCABG group. The tricuspid E/A ratio decreased significantly in both groups. Peak systolic velocity of the lateral tricuspid annulus $\left(\mathrm{S}_{\mathrm{a}}\right)$ was unchanged in the CCABG group but decreased in the OPCAB group; the intergroup difference did not reach statistical significance. Diastolic tricuspid annular peak velocity $\mathrm{E}_{\mathrm{a}}$ decreased significantly in the OPCAB group only; the intergroup difference at the end of surgery was not statistically significant. All these findings were similar when only considering patients according to the surgical technique or patients who had not received inotropic support at the end of surgery (12 patients in the CCABG group and 18 patients in the OPCAB group; data not given in detail). Systolic LV fractional area change remained unchanged in both groups. The LV end-diastolic and end-systolic areas decreased after surgery only in the CCABG group, but intergroup differences were not statistically significant. New segmental wall motion abnormalities were found after surgery in 7 patients in the OPCAB group and in 5 patients in the CCABG group. New wall motion abnormalities in the area supplied by the right coronary artery, that is, in the inferior segments, were found in 4 and in 2 patients in the OPCAB and CCABG groups, respectively. There were no intergroup differences in the overall wall motion score index based on all 16 segments and in the wall motion score index of the 3 inferior segments, although the index of the inferior segments strongly tended to increase after surgery in the OPCAB group $(P=.052)$.

\section{Discussion}

The hypothesis that OPCAB surgery would better preserve $\mathrm{RV}$ systolic and diastolic functions than CCABG surgery was not confirmed by this randomized echocardiographic study. Cardiac output and RV systolic ejection fraction were preserved at the end of coronary surgery after both CCABG and OPCAB surgery. In contrast, RV diastolic function was similarly impaired after revascularization, as indicated by significantly smaller E/A ratios and markedly decreased end-diastolic volumes. Analysis of lateral tricuspid annular motion revealed impaired systolic and diastolic function only in the OPCAB group, but intergroup differences were not statistically significant. Given the unchanged ejection fraction but decreased end-diastolic volume, the finding of preserved cardiac output after surgery reflects adequate management of the heart rate according to published standards for CCABG patients ${ }^{15}$ and OPCAB patients. ${ }^{16}$ The heart rate was higher after surgery than at baseline for both groups, and it was higher for CCABG patients than for OPCAB patients. Cardiac output values thus showed that global cardiac function was sufficiently preserved for achieving and maintaining the circulatory goals both after CCABG and after 
TABLE 2. Intraoperative characteristics of 50 patients undergoing on-pump (CCABG) versus off-pump (OPCAB) coronary artery bypass surgery

\begin{tabular}{|c|c|c|c|}
\hline & CCABG & OPCAB & $P$ value \\
\hline Patients & 25 & 25 & \\
\hline Anastomoses & $3.2 \pm 0.7[3.0]$ & $2.9 \pm 0.6[3.0]$ & .086 \\
\hline Revascularization to RCA & $21(84)$ & $19(76)$ & .725 \\
\hline Cardiopulmonary bypass time (min) & $82 \pm 24[78]$ & $92 / 81 \dagger$ & \\
\hline Aortic crossclamp time (min) & $49 \pm 14[47]$ & $50 / 56 \dagger$ & \\
\hline \multicolumn{4}{|l|}{ Intraoperative fluid administration } \\
\hline Ringer's lactate (mL) & $3798 \pm 983[3700]$ & $2630 \pm 1116[2400]$ & .001 \\
\hline Hydroxyethyl starch 6\% (mL) & $868 \pm 390[1000]$ & $854 \pm 399[1000]$ & .442 \\
\hline \multicolumn{4}{|l|}{ Allogeneic blood transfusion } \\
\hline Patients receiving transfusion & $14(56)$ & $4(16)$ & .007 \\
\hline Units of blood per patient & $1.2 \pm 1.3[1.0]$ & $0.2 \pm 0.5[0.0]$ & .007 \\
\hline Hemoglobin at baseline (g/L) & $125 \pm 15[129]$ & $126 \pm 11[126]$ & .724 \\
\hline Hemoglobin at the end of surgery $(\mathrm{g} / \mathrm{L})$ & $94 \pm 13[90]$ & $103 \pm 10[104]$ & .001 \\
\hline Urine output (mL) & $574 \pm 201[580]$ & $483 \pm 298[430]$ & .048 \\
\hline \multicolumn{4}{|l|}{ Intraoperative cardiovascular medication } \\
\hline Epinephrine, infusion pump & $13(52)$ & $7(27)$ & .148 \\
\hline Norepinephrine, infusion pump & $8(32)$ & $6(24)$ & .754 \\
\hline Beta-blocker, boluses & $5(20)$ & $9(36)$ & .345 \\
\hline Atrial pacing at the end of surgery & $15(60)$ & $5(20)$ & .008 \\
\hline \multicolumn{4}{|l|}{ Heart rate (beats/min) } \\
\hline Baseline & $60 \pm 9[58]$ & $65 \pm 9[63]$ & .068 \\
\hline End of surgery & $92 \pm 8[90]$ & $82 \pm 10[82]$ & $<.001$ \\
\hline \multicolumn{4}{|l|}{ Mean arterial pressure $(\mathrm{mm} \mathrm{Hg})$} \\
\hline Baseline & $73 \pm 12[72]$ & $76 \pm 11[77]$ & .232 \\
\hline End of surgery & $77 \pm 13[78]$ & $77 \pm 9[78]$ & .938 \\
\hline \multicolumn{4}{|l|}{ Central venous pressure (mm Hg) } \\
\hline Baseline & $9 \pm 3[9]$ & $9 \pm 5[9]$ & .623 \\
\hline End of surgery & $9 \pm 4[9]$ & $10 \pm 5[9]$ & .694 \\
\hline \multicolumn{4}{|l|}{ Mean pulmonary artery pressure $(\mathrm{mm} \mathrm{Hg})^{*}$} \\
\hline Baseline & $16 \pm 2[16]$ & $19 \pm 6[17]$ & .752 \\
\hline End of surgery & $23 \pm 8[21]$ & $19 \pm 6[19]$ & .450 \\
\hline Peak troponin I in first 24 hours after surgery & $54 \pm 95[14]$ & $43 \pm 80[4]$ & .049 \\
\hline
\end{tabular}

Values for continuous variables represent mean $\pm \mathrm{SD}$ [median]. Values for categorical variables are number (\%). RCA, Right coronary artery. *All patients in the OPCAB group but only 4 patients in the CCABG group had a pulmonary artery catheter inserted. $†$ Only 2 patients in the OPCAB group underwent cardiopulmonary bypass. Numbers represent the individual times of these 2 patients.

OPCAB surgery. However, preserved cardiac output is not an indicator of unimpaired RV myocardial function.

Impairment of RV diastolic myocardial function both after CCABG surgery and after OPCAB surgery was indicated by the marked decreases in the $\mathrm{E} / \mathrm{A}$ ratios at the end of surgery for both groups. Impaired diastolic function also accounted for the significant decreases in end-diastolic volume after surgery, as did the markedly higher heart rates. The degree to which the significantly higher heart rate or the higher degree of diastolic dysfunction contributed to the significantly larger decrease in end-diastolic volume in the CCABG group cannot be differentiated.

Tricuspid annular velocities were assessed in the lateral area because they are primarily influenced by the RV free wall. Our interest was directed to the RV free wall because this wall is more compressed than the left ventricle in a porcine model of OPCAB surgery, with displacement of the beating heart resulting primarily in $\mathrm{RV}$ dysfunction. ${ }^{17}$ Peak systolic and early diastolic velocities of the lateral tricuspid annulus, $\mathrm{S}_{\mathrm{a}}$ and $\mathrm{E}_{\mathrm{a}}$, were studied as indicators of systolic and diastolic myocardial function. These two parameters are predictive of cardiac complications and death in nonsurgical patients with symptomatic heart failure. ${ }^{18}$ In our study, there were no statistically significant intergroup differences in these two parameters after CCABG versus OPCAB surgery. Nevertheless, there was a small but statistically significant decrease in peak systolic tricuspid annular velocity in the OPCAB group, whereas it remained unchanged in the $\mathrm{CCABG}$ group. The more frequent use of atrial pacing in the CCABG group might have contributed to this result because atrial pacing increases RV inotropic status after coronary surgery. ${ }^{19}$ In contrast, epinephrine with its positive 
TABLE 3. Echocardiographic parameters in 50 patients undergoing on-pump (CCABG) versus off-pump (OPCAB) coronary artery bypass surgery

\begin{tabular}{|c|c|c|c|c|c|}
\hline & \multicolumn{2}{|c|}{ CCABG (n = 25) } & \multicolumn{2}{|c|}{ OРCAB (n = 25) } & \multirow{2}{*}{$\begin{array}{c}\begin{array}{c}\text { Intergroup } \\
\text { comparison at } \\
\text { end surgery }\end{array} \\
P \text { value } \\
\end{array}$} \\
\hline & Baseline & End & Baseline & End & \\
\hline \multicolumn{6}{|l|}{ RV parameters } \\
\hline Cardiac output & $2603 \pm 579[2535]$ & $3095 \pm 1180$ [2944] & $2915 \pm 1156$ [2820] & $3291 \pm 987$ [3195] & 0.455 \\
\hline $\mathrm{EF} \%$ & $48 \pm 8[48]$ & $46 \pm 11[48]$ & $45 \pm 7[45]$ & $46 \pm 9[47]$ & 0.553 \\
\hline EDV (ml) & $91 \pm 24[94]$ & $73 \pm 23[67] \ddagger$ & $98 \pm 25[98]$ & $89 \pm 23[83]^{*}$ & 0.022 \\
\hline ESV (ml) & $47 \pm 15[49]$ & $39 \pm 15[36] \dagger$ & $54 \pm 15[50]$ & $49 \pm 15[49]^{*}$ & 0.039 \\
\hline$E / A$ & $1.2 \pm 0.3[1.2]$ & $0.9 \pm 0.3[0.9] \dagger$ & $1.3 \pm 0.4[1.3]$ & $0.8 \pm 0.2[0.9] \dagger$ & 0.562 \\
\hline $\mathrm{S}_{\mathrm{a}-\mathrm{lat}}(\mathrm{cm} / \mathrm{s})$ & $6.8 \pm 1.5[6.7]$ & $6.7 \pm 1.9[6.6]$ & $7.2 \pm 1.3[7.1]$ & $6.1 \pm 1.7[6.0] \dagger$ & 0.341 \\
\hline $\mathrm{E}_{\mathrm{a}-\mathrm{lat}}(\mathrm{cm} / \mathrm{s})$ & $5.3 \pm 1.4[5.4]$ & $4.7 \pm 1.7[4.3]$ & $6.0 \pm 1.4[6.1]$ & $4.0 \pm 1.8[4.0] \dagger$ & 0.246 \\
\hline \multicolumn{6}{|l|}{ LV parameters } \\
\hline FAC $(\%)$ & $45 \pm 14[48]$ & $46 \pm 17[45]$ & $47 \pm 13$ [49] & $48 \pm 14[51]$ & 0.808 \\
\hline $\mathrm{EDA}\left(\mathrm{cm}^{2}\right)$ & $17 \pm 5[17]$ & $14 \pm 4[13] \dagger$ & $17 \pm 5[16]$ & $16 \pm 7[14]$ & 0.240 \\
\hline $\mathrm{ESA}\left(\mathrm{cm}^{2}\right)$ & $9 \pm 4[8]$ & $8 \pm 4[7] \dagger$ & $9 \pm 5[8]$ & $9 \pm 6[7]$ & 0.491 \\
\hline$E / A$ & $1.0 \pm 0.5[0.9]$ & $0.9 \pm 0.2[0.8]$ & $1.2 \pm 0.4[1.0]$ & $1.0 \pm 0.3[0.9]^{*}$ & 0.108 \\
\hline WMSI (16 segments) & $1.48 \pm 0.57[1.28]$ & $1.46 \pm 0.61[1.28]$ & $1.48 \pm 0.66[1.19]$ & $1.58 \pm 0.70[1.37]$ & 0.347 \\
\hline WMSI-RCA & $1.44 \pm 0.43[1.00]$ & $1.36 \pm 0.77[1.00]$ & $1.41 \pm 0.62[1.00]$ & $1.66 \pm 0.94[1.00] \S$ & 0.285 \\
\hline
\end{tabular}

Values are mean $\pm S D$ [median]. End, End of surgery (sternum closed); $R V$, right ventricular; $E F$, ejection fraction; $E D V$, end-diastolic volume; $E S V$, end-systolic volume; $E / A$, ratio of early peak diastolic velocity and late peak diastolic velocity of tricuspid inflow and mitral inflow, respectively; $S_{a}$, peak systolic velocity of the posterolateral tricuspid annulus; $E_{a}$, early peak diastolic velocity of the posterolateral tricuspid annulus; $L V$, left ventricular; $F A C$, fractional area change; EDA, end-diastolic area; $E S A$, end-systolic area; WMSI, wall motion score indices; WMSI-RCA, wall motion score indices for the segments depending on the right coronary artery. $* P \leq .05, \dagger P<.01, \ddagger P<.001, \S P=.052$ : compared with baseline values (intragroup comparisons).

inotropic effect did not confound the result because the findings of $S_{a}$, as well as of $E_{a}$, did not differ when only patients were analyzed who did not receive epinephrine. Diastolic function, as indicated by diastolic tricuspid annular velocity $E_{a}$, was significantly impaired only in the OPCAB group, but the intergroup difference was not statistically significant. The decrease in the OPCAB group might have been influenced by the decrease in $S_{a}$ because $E_{a}$ is not independent of systolic velocity. ${ }^{20}$ In contrast, the changed heart rates did not confound the result because diastolic velocities are not significantly influenced by heart rate or altered pulmonary arterial pressure. ${ }^{20}$ Taken together, tricuspid annular velocities suggest significantly impaired systolic and diastolic myocardial function of the RV lateral free wall at the end of coronary surgery only in the OPCAB group, but intergroup differences were not statistically significant. These findings do not allow for drawing final conclusions on the relative degree of RV dysfunction shortly after CCABG versus OPCAB surgery but clearly do not support our hypothesis that OPCAB surgery would better preserve RV function.

$\mathrm{RV}$ dysfunction is a widely known phenomenon after CCABG surgery. ${ }^{21-24}$ Its importance was demonstrated as early as 1985 , when a study found transiently impaired RV performance after CCABG surgery but maintained LV performance. ${ }^{22}$ Similar to the present study, recent investigations have used tricuspid annular velocities to assess RV function after CCABG surgery. ${ }^{21,23,24}$ The studies found markedly compromised tricuspid annular velocities after CCABG surgery that persisted at follow-up studies $6^{24}$ and 12 months after surgery. ${ }^{21}$ Occurrence and severity of RV dysfunction after OPCAB surgery has been studied less in detail. Two published studies used invasive catheterization in patients undergoing $\mathrm{OPCAB}$ surgery and focused primarily on the short-term effects of cardiac displacement on hemodynamic parameters. ${ }^{25,26}$ The investigators found the most profound derangement of RV function during cardiac positioning for the circumflex artery and its branches. ${ }^{25,26}$ They suggested that the major cause of hemodynamic changes is disturbed diastolic filling of the right ventricle, ${ }^{25}$ and they found that sternal closure enhanced recovery of decreased cardiac output. ${ }^{26}$ However, markedly impaired cardiac function can be of clinical importance even if it recovers by the end of OPCAP surgery: for example, jugular bulb desaturations that indicate insufficient cerebral perfusion occur more frequently during OPCAB than CCABG surgery. ${ }^{27}$ Our present study did not focus on the immediate effects of cardiac displacement but rather on the effects of coronary surgery on RV function that persist at the end of surgery, and it prospectively compared CCABG versus OPCAB surgery. RV dysfunction that persisted at the end of surgery despite avoidance of cardiopulmonary bypass in the OPCAB group most likely was caused by direct compression of the RV during cardiac displacement ${ }^{17,25}$ and by effects of repeated transient ischemia. Persisting RV dys- 

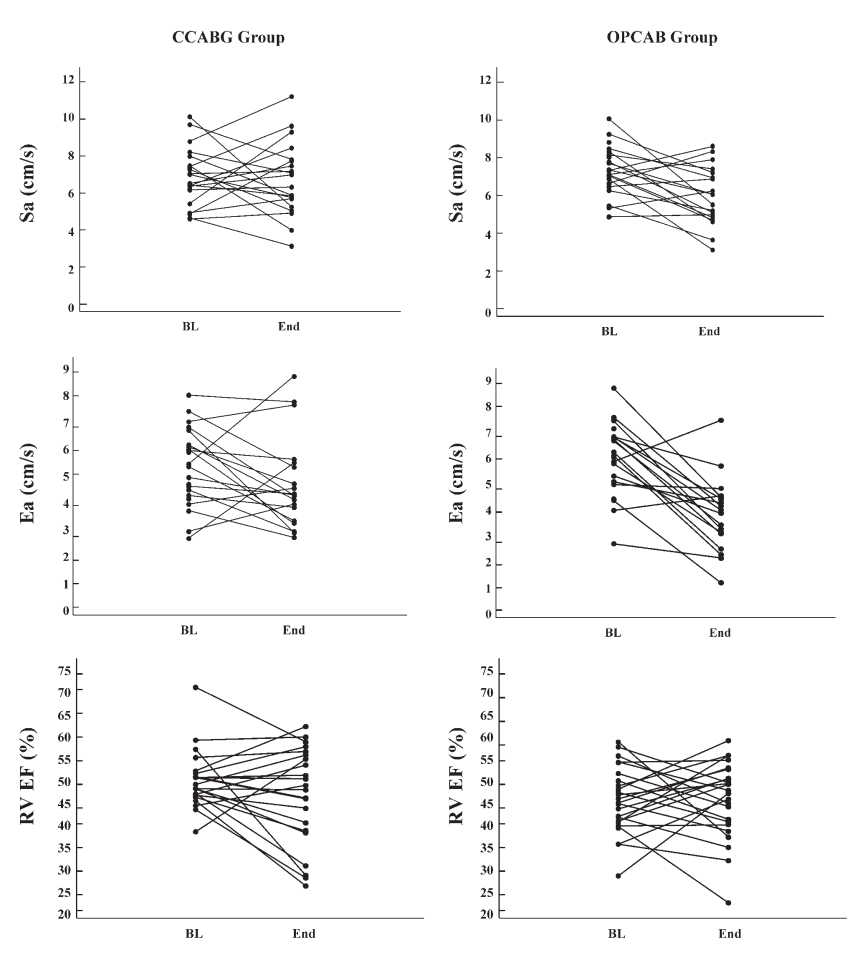

Figure 1. Echocardiographic parameters of systolic and diastolic right ventricular functions at baseline and at the end of surgery in 25 patients undergoing conventional on-pump coronary bypass surgery (CCABG) versus 25 patients undergoing off-pump coronary bypass surgery (OPCAB). Sa, Peak systolic velocity of the posterolateral tricuspid annulus; $E a$, early peak diastolic velocity of the posterolateral tricuspid annulus; $R V$, right ventricular; $E F$, ejection fraction; $B L$, baseline.

function in our OPCAB group was indicated by the TDI parameters (Table 3), whereas because of the lack of established methods we did not search for new ischemic wall motion abnormalities in the right ventricle, as is commonly performed in the left ventricle. One can only speculate that the new wall motion abnormalities in inferior LV segments after surgery in 4 patients and a strong trend toward deterioration of the $\mathrm{LV}$ inferior wall motion score index in the OPCAB group (Table 3) might have indicated persisting effects of ischemia in the whole supply area of the right coronary artery, that is, also in most parts of the RV. Overall, we found persisting new systolic wall motion abnormalities in LV segments in approximately a quarter of our patients. LV diastolic function was not a main focus of the present study, although impairment of diastolic function in the OPCAB group was suggested by a decrease in the mitral E/A ratio. A detailed assessment of the effects of OPCAB and CCABG surgery on LV diastolic function was performed by $\mathrm{Ng}$ and colleagues, ${ }^{28}$ who reported an improvement of diastolic function in both groups that was more pronounced in the CCABG group.
Our findings of less need for blood transfusion and higher hemoglobin values in the OPCAB group were consistent with previous studies, ${ }^{7,29}$ as was the finding of higher peak troponin I levels in the CCABG very early after surgery. ${ }^{6-8,29}$ The clinical significance of the difference in early myocardial enzyme release is unclear, as two studies reported that initial differences in enzyme release between CCABG and OPCAB groups disappeared as early as 24 hours after surgery.

A limitation of the study was that the average heart rates were not identical in both groups at the end of surgery. This difference complicates interpretation of intergroup differences because the heart rate has an effect on systolic function $^{19}$ and on end-diastolic volume. ${ }^{30}$ However, the heart rate was managed according to clinical practice ${ }^{15,16}$ and the preserved cardiac output in both groups indicated its adequacy. Another limitation is that our patients did not have marked preexisting RV dysfunction, which limits the generality of the present findings. One can speculate that preexisting RV dysfunction will be more affected by CCABG or OPCAB surgery than normal RV function. If one of these surgical methods were to produce less impairment of RV function, this could be crucial in patients with preexisting $\mathrm{RV}$ dysfunction.

In conclusion, OPCAB surgery did not better preserve RV systolic and diastolic function than CCABG surgery. Cardiac output and RV systolic ejection fraction were preserved at the end of CCABG and OPCAB surgery, and global RV diastolic function was similarly impaired in both groups. Lateral tricuspid annular velocities suggest impaired myocardial function of the RV lateral free wall only in the OPCAB group, but intergroup differences were not statistically significant.

We thank Esther Seeberger and Claudia Werner, Department of Anesthesia, University Hospital of Basel, for help with data acquisition and Joan Etlinger, Department of Anesthesia University Hospital of Basel, for editorial assistance. We also thank Jacques Jamart, Department of Biostatistics, University Clinics of Mont Godinne, Université Catholique de Louvain, Yvoir, Belgium, for statistical assistance.

\section{References}

1. Davila-Roman VG, Waggoner AD, Hopkins WE, Barzilai B. Right ventricular dysfunction in low output syndrome after cardiac operations: assessment by transesophageal echocardiography. Ann Thorac Surg. 1995;60:1081-6.

2. Reichert CL, Visser CA, van den Brink RB, Koolen JJ, van Wezel HB, Moulijn AC, et al. Prognostic value of biventricular function in hypotensive patients after cardiac surgery as assessed by transesophageal echocardiography. J Cardiothorac Vasc Anesth. 1992;6:429-32.

3. Ascione R, Caputo M, Angelini GD. Off-pump coronary artery bypass grafting: not a flash in the pan. Ann Thorac Surg. 2003;75:306-13.

4. Rose EA. Off-pump coronary-artery bypass surgery. $N$ Engl J Med. 2003;348:379-80.

5. Sellke FW, DiMaio JM, Caplan LR, Ferguson TB, Gardner TJ, Hiratzka LF, et al. Comparing on-pump and off-pump coronary artery bypass grafting: numerous studies but few conclusions-a scientific statement from the American Heart Association council on cardiovascular surgery and anesthesia in collaboration with the interdisciplinary 
working group on quality of care and outcomes research. Circulation. 2005;111:2858-64.

6. Gerola LR, Buffolo E, Jasbik W, Botelho B, Bosco J, Brasil LA, et al. Off-pump versus on-pump myocardial revascularization in low-risk patients with one or two vessel disease: perioperative results in a multicenter randomized controlled trial. Ann Thorac Surg. 2004;77: 569-73.

7. Puskas JD, Williams WH, Duke PG, Staples JR, Glas KE, Marshall JJ, et al. Off-pump coronary artery bypass grafting provides complete revascularization with reduced myocardial injury, transfusion requirements, and length of stay: a prospective randomized comparison of two hundred unselected patients undergoing off-pump versus conventional coronary artery bypass grafting. $J$ Thorac Cardiovasc Surg. 2003;125:797-808.

8. Straka Z, Widimsky P, Jirasek K, Stros P, Votava J, Vanek T, et al. Off-pump versus on-pump coronary surgery: final results from a prospective randomized study PRAGUE-4. Ann Thorac Surg. 2004; 77:789-93

9. Royse CF, Royse AG, Wong CT. Assessment of left ventricular function during off-pump coronary artery bypass surgery. Ann Thorac Cardiovasc Surg. 2003;9:371-7.

10. Wang J, Filipovic M, Rudzitis A, Michaux I, Skarvan K, Buser P, et al. Transesophageal echocardiography for monitoring segmental wall motion during off-pump coronary artery bypass surgery. Anesth Analg. 2004;99:965-73.

11. Skarvan K, Filipovic M, Wang J, Brett W, Seeberger M. Use of myocardial tissue Doppler imaging for intraoperative monitoring of left ventricular function. Br J Anaesth. 2003;91:473-80.

12. Sergeant P, de Worm E, Meyns B, Wouters P. The challenge of departmental quality control in the reengineering towards off-pump coronary artery bypass grafting. Eur J Cardiothorac Surg. 2001;20: 538-43.

13. Denslow S, Wiles HB. Right ventricular volumes revisited: a simple model and simple formula for echocardiographic determination. $J \mathrm{Am}$ Soc Echocardiogr. 1998;11:864-73.

14. Shanewise JS, Cheung AT, Aronson S, Stewart WJ, Weiss RL, Mark $\mathrm{JB}$, et al. ASE/SCA guidelines for performing a comprehensive intraoperative multiplane transesophageal echocardiography examination: recommendations of the American Society of Echocardiography Council for Intraoperative Echocardiography and the Society of Cardiovascular Anesthesiologists Task Force for Certification in Perioperative Transesophageal Echocardiography. Anesth Analg. 1999;89: 870-84.

15. Romanoff ME, Larach DR. Weaning from cardioplumonary bypass. In: Hensley FA, Martin DE, Gravlee GP, editors. A practical approach to cardiac anesthesia. Philadelphia: Lippincott Williams \& Wilkins; 2003. p. 221-34.

16. Nierich AP, Diephuis J, Jansen EW, van Dijk D, Lahpor JR, Borst C, et al. Embracing the heart: perioperative management of patients undergoing off-pump coronary artery bypass grafting using the Octopus tissue stabilizer. J Cardiothorac Vasc Anesth. 1999;13:123-9.
17. Grundeman PF, Borst C, Verlaan CW, Meijburg H, Moues CM, Jansen EW. Exposure of circumflex branches in the tilted, beating porcine heart: echocardiographic evidence of right ventricular deformation and the effect of right or left heart bypass. J Thorac Cardiovasc Surg. 1999;118:316-23.

18. Meluzin J, Spinarova L, Hude P, Krejci J, Kincl V, Panovsky R, et al. Prognostic importance of various echocardiographic right ventricular functional parameters in patients with symptomatic heart failure. $J \mathrm{Am}$ Soc Echocardiogr. 2005;18:435-44.

19. Lancon JP, Pillet M, Gabrielle F, Fayolle JL, Tatou E. Effects of atrial pacing on right ventricular contractility after coronary artery surgery. J Cardiothorac Vasc Anesth. 1994;8:536-40.

20. Nageh MF, Kopelen HA, Zoghbi WA, Quinones MA, Nagueh SF. Estimation of mean right atrial pressure using tissue Doppler imaging. Am J Cardiol. 1999;84:1448-51.

21. Alam M, Hedman A, Nordlander R, Samad B. Right ventricular function before and after an uncomplicated coronary artery bypass graft as assessed by pulsed wave Doppler tissue imaging of the tricuspid annulus. Am Heart J. 2003;146:520-6.

22. Christakis GT, Fremes SE, Weisel RD, Ivanov J, Madonik MM, Seawright SJ, et al. Right ventricular dysfunction following cold potassium cardioplegia. J Thorac Cardiovasc Surg. 1985;90:243-50.

23. Mishra M, Swaminathan M, Malhotra R, Mishra A, Trehan N. Evaluation of right ventricular function during $\mathrm{CABG}$ : transesophageal echocardiographic assessment of hepatic venous flow versus conventional right ventricular performance indices. Echocardiography. 1998; 15:51-8.

24. Wranne B, Pinto FJ, Hammarstrom E, St Goar FG, Puryear J, Popp RL. Abnormal right heart filling after cardiac surgery: time course and mechanisms. Br Heart J. 1991;66:435-42.

25. Mathison M, Edgerton JR, Horswell JL, Akin JJ, Mack MJ. Analysis of hemodynamic changes during beating heart surgical procedures. Ann Thorac Surg. 2000;70:1355-60; discussion 60-1.

26. Kwak YL, Oh YJ, Jung SM, Yoo KJ, Lee JH, Hong YW. Change in right ventricular function during off-pump coronary artery bypass graft surgery. Eur J Cardiothorac Surg. 2004;25:572-7.

27. Diephuis JC, Moons KG, Nierich AN, Bruens M, van Dijk D, Kalkman CJ. Jugular bulb desaturation during coronary artery surgery: a comparison of off-pump and on-pump procedures. Br J Anaesth. 2005;94:715-20.

28. Ng KK, Popovic ZB, Troughton RW, Navia J, Thomas JD, Garcia MJ. Comparison of left ventricular diastolic function after on-pump versus off-pump coronary artery bypass grafting. Am J Cardiol. 2005;95:647-50.

29. Khan NE, De Souza A, Mister R, Flather M, Clague J, Davies S, et al. A randomized comparison of off-pump and on-pump multivessel coronary-artery bypass surgery. N Engl J Med. 2004;350:21-8.

30. Arentzen CE, Rankin JS, Anderson PA, Feezor MD, Anderson RW. Force-frequency characteristics of the left ventricle in the conscious dog. Circ Res. 1978;42:64-71. 